EASTERN REVIEW 2018, T. 7

\title{
Wybrane pozycje bibliograficzne z problematyki rozwoju społeczeństwa obywatelskiego oraz funkcjonowania samorządu lokalnego w latach 1996-2017
}

\section{Dokumenty}

Archiwum Akt Nowych, KC PZPR, sygn. III/196.

Konstytucja Rzeczypospolitej Polskiej z dnia 2 kwietnia 1997 r. (Dz.U. 1997, nr 78, poz. 483).

Obwieszczenie Państwowej Komisji Wyborczej z dnia 10 grudnia 1990 r. o wynikach ponownego głosowania i wyniku wyborów Prezydenta Rzeczypospolitej Polskiej (Dz.U., nr 85, poz. 499).

Obwieszczenie Państwowej Komisji Wyborczej z dnia 11 maja 2015 r. - o wynikach głosowania i wyniku wyborów Prezydenta Rzeczypospolitej Polskiej, zarządzonych na dzień 10 maja 2015 r. (Dz.U. 2015, poz. 650).

Obwieszczenie Państwowej Komisji Wyborczej z dnia 20 lutego 1996 r. o wynikach głosowania i wynikach referendów przeprowadzonych w dniu 18 lutego 1996 r. (Dz.U., nr 22, poz. 101)

Obwieszczenie Państwowej Komisji Wyborczej z dnia 26 listopada 1990 r. o wynikach głosowania i wyniku wyborów Prezydenta Rzeczypospolitej Polskiej, zarządzonych na dzień 25 listopada 1990 r. (Dz.U., nr 83, poz. 483).

Obwieszczenie Państwowej Komisji Wyborczej z dnia 30 października 1991 r. - o wynikach wyborów do Senatu, przeprowadzonych w dniu 17 października 1991 r. (M.P., nr 41, poz. 287).

Obwieszczenie Państwowej Komisji Wyborczej z dnia 31 października 1991 r. - o wynikach wyborów do Sejmu przeprowadzonych 27 października 1991 r. (M.P., nr 41, poz. 288).

Oceny działalności parlamentu i prezydenta, BS/94/2005, Komunikat z Badań CBOS, Warszawa 2005.

Ogłoszenie Generalnego Komisarza w sprawie głosowania ludowego o wyniku głosowania ludowego z dnia 30 czerwca 1946 r. (M.P., nr 61, poz. 115). 
Po co nam budżet obywatelski. Poradnik skutecznej partycypacji dla pracowników samorząowych, Urząd Marszałkowski Województwa Małopolskiego, Kraków 2016.

Poselski projekt ustawy o zmianie ustawy o kombatantach oraz niektórych osobach będacych ofiarami represji wojennych i okresu powojennego oraz niektórych innych ustaw, Druk sejmowy nr 428, Sejm VII kadencji, http://www. sejm.gov.pl/Sejm8.nsf/druk.xsp?nr=428 (dostęp 8.09.2016).

Poselski projekt ustawy o zmianie ustawy o Policji oraz niektórych innych ustaw,

Druk sejmowy nr 154, IV kadencja Sejmu, http://www.sejm.gov.pl/Sejm8. nsf/druk.xsp?nr=154 (dostęp 20.10.2016).

Poselski projekt ustawy o zmianie ustawy o samorzadzie gminnym oraz o zmianie innych ustaw, Druk sejmowy nr 3834, Sejm VI kadencji, http://orka.sejm. gov.pl/Druki6ka.nsf/wgdruku/3834 (dostęp 10.10.2016).

Rada Miejska obnizyła pensję prezydent Zdanowskiej, „Urząd Miasta Łodzi”, 18.06.2014, http://www.uml.lodz.pl/samorzad/aktualnosci/?news=26058 (dostęp 15.11.2016).

Radni województwa przyjęli regulamin budżetu obywatelskiego, https://bo.malopolska.pl/index.php/wydarzenia/15-radni-wojewodztwa-przyjeli-regulaminbudzetu-obywatelskiego (dostęp 20.02.2017).

Raport Kancelarii Prezydenta RP nt. referendów lokalnych, www.prezydent.pl (dostęp 21.12.2016).

Raport końcowy z badania efektywności mechanizmów konsultacji społecznych,

Ministerstwo Pracy i Polityki Społecznej oraz MillwardBrown SMG/KRC, 43/DPP/PN/2009, Warszawa 2011.

Raport ,Najlepsze działania promocyjne polskich miast i regionów. Edycja 20152016", http://marketingmiejsca.com.pl/media/uploaded/raportpaw48nyvsn3/ Raport_Najlepsze_dzialania_promo_polskich_miast_i_regionow_Raport_ 2015-2016.pdf (dostęp 16.09.2016).

Raport z ewaluacji BO Małopolska, https://bo.malopolska.pl/index.php/wydarzenia/61mieszkancy-zadowoleni-z-realizacji-bo-malopolska (dostęp 20.02.2017).

Regulamin Budżetu Obywatelskiego Województwa Małopolskiego, http://bip.malopolska.pl/umwm/Article/get/id,1139998.html (dostęp 20.02.2017).

Sprawozdanie stenograficzne z 33. posiedzenia Sejmu RP, http://www.sejm.gov. pl/Sejm8.nsf/stenogramy.xsp?rok=2016 (dostęp 10.10.2016).

Statut Związku Polaków na Litwie.

Stenogram z 87. posiedzenia Sejmu VI kadencji, http://orka2.sejm.gov.pl/StenoInter6.nsf/main?OpenForm\#top (dostęp 9.10.2016).

Strategia Rozwoju Województwa Pomorskiego 2020, Gdańsk 2012, http://strategia2020.pomorskie.eu/documents/240306/400793/Pomorskie_SRWP2020. pdf/d1f b1e1b-4c73-4221-8f2b-8cff5b3a9f45 (dostęp 10.04.2017).

Traktat o Unii Europejskiej, https://polskawue.gov.pl/files/polska_w_ue /prawo/ traktaty/ Traktat_z_Maastricht.pdf (dostęp 29.12.2015). 
Uchwała nr 1272/190/12 Zarządu Województwa Pomorskiego z dnia 30 października $2012 \mathrm{r}$.

Uchwała nr XVI/223/15 Sejmiku Województwa Małopolskiego z dnia 23 listopada 2015 r. w sprawie konsultacji wojewódzkich dotyczących projektu Budżetu Obywatelskiego Województwa Małopolskiego, http://bip.malopolska. pl/umwm/Article/get/id,1139998.html (dostęp 20.02.2017).

Uchwała Sądu Najwyższego z dnia 15 lipca 1997 r. w sprawie ważności referendum konstytucyjnego przeprowadzonego w dniu 25 maja 1997 r. (Dz.U., nr 79, poz. 490).

Uchwała Sejmu Rzeczypospolitej Polskiej z dnia 21 grudnia 1995 r. w sprawie przeprowadzenia referendum o niektórych kierunkach wykorzystania majątku państwowego (Dz.U., nr 154, poz. 795).

Ustawa Konstytucyjna z dnia 23 kwietnia 1992 r. o trybie przygotowania i uchwalenia Konstytucji Rzeczypospolitej Polskiej (Dz.U. 1992, nr 67, poz. 336).

Ustawa o samorządzie powiatowym (Dz.U.2015.1445).

Ustawa o samorządzie terytorialnym (Dz.U.2016.446).

Ustawa o samorządzie województwa (Dz.U.2016.486).

Ustawa Republiki Litewskiej o częściowej zmianie i uzupełnieniu Ustawy wyborczej do Sejmu Republiki Litewskiej (1993).

Ustawa Republiki Litewskiej o wyborach deputowanych do Rad Samorządowych (1989).

Ustawa Republiki Litewskiej o wyborach do Rad Samorządowych (1994).

Ustawa Ukrainy $O$ partiach politycznych w Ukrainie (2001), http://zakon3.rada. gov.ua/laws/show/2365-14 (dostęp 29.12.2015).

Ustawa Ukrainy $O$ wniesienie zmian do niektórych aktów prawnych w celu zapobiegania i przeciwdziatania korupcji politycznej (2015), http://zakon2.rada. gov.ua/laws/show/731-19 (dostęp 29.12.2014).

Ustawa z dnia 5 stycznia 2011 r. Kodeks wyborczy (Dz.U. 2011, nr 21, poz. 112).

Ustawa z dnia 6 grudnia 2006 r. o zasadach prowadzenia polityki rozwoju (Dz.U. 2009, $\mathrm{nr}$ 84, poz. 712; nr 157, poz.1241).

Ustawa z dnia 12 kwietnia 2001 r. Ordynacja wyborcza do Sejmu Rzeczypospolitej Polskiej i Senatu Rzeczypospolitej Polskiej (Dz.U., nr 46, poz. 499 z późn. zm.).

Ustawa z dnia 16 lipca 1998 r. Ordynacja wyborcza do rad gmin, rad powiatów i sejmików województw (Dz.U., nr 95, poz. 602 z późn. zm.).

Ustawa z dnia 20 czerwca 2002 r., o bezpośrednim wyborze wójta, burmistrza i prezydenta miasta (Dz. U., nr 113, poz. 984).

Ustawa z dnia 23 stycznia 2004 r. Ordynacja wyborcza do Parlamentu Europejskiego (Dz.U., nr 25, poz. 219 z późn. zm.).

Ustawa z dnia 27 września 1990 r., o wyborze Prezydenta Rzeczypospolitej Polskiej (Dz.U., nr 67, poz. 398 z późn. zm.).

W budżecie. Wyniki I edycji budzetu obywatelskiego, https://bo.malopolska.pl/index.php/obudzecie (dostęp 20.02.2017). 
Wykaz komitetów wyborczych, które zgłosity kandydatów na senatorów w więcej niż jednym województwie, [w:] Wyniki wyborów do Senatu Rzeczypospolitej Polskiej z 27 października 1991 r., Warszawa 1991.

Wykaz Komitetów wyborczych wedtug wylosowanych numerów list kandydatów,

[w:] Wyniki wyborów do Sejmu Rzeczypospolitej Polskiej z 27 października 1991 r., Warszawa 1991.

Wyniki ankiety ewaluacyjnej II edycji Budżetu Obywatelskiego dla Łodzi, http:// uml.lodz.p1/budzet_obywatelski/budzet_obywatelski_na_2015/ewaluacja/ (dostęp 28.04.2016).

Wyniki ankiety ewaluacyjnej III edycji Budżetu Obywatelskiego dla Łodzi, http:// uml.lodz.pl/get.php?id=15091 (dostęp 28.04.2016).

Wypowiedź prof. Piotra Winczorka na posiedzeniu Komisji Ustawodawczej w dniu 8 stycznia 2003 r., ,Biuletyn Komisji Ustawodawczej Sejmu IV kadencji”, nr 1380/IV.

Wypowiedź profesora Jana Poleszuka z Uniwersytetu w Białymstoku w TVP Białystok 7 września $2015 \mathrm{r}$.

Wystąpienie Józefa Florka podczas XIII Plenum KC PZPR w dniu 29 lipca 1989 r., Archiwum Akt Nowych, KC PZPR, sygn. III/196.

XVI Sesja Sejmiku Województwa Małopolskiego, https://bo.malopolska.pl/index.php/wydarzenia/14-xvi-sesja-sejmiku-wojewodztwamalopolskiego (dostęp 20.02.2017).

Zarządzenie Prezydenta Rzeczypospolitej Polskiej z dnia 29 listopada 1995 r. $\mathrm{w}$ sprawie przeprowadzenia referendum o powszechnym uwłaszczeniu obywateli (Dz.U., nr 138, poz. 685).

Zasady dialogu spolecznego: dokument programowy rzadu przyjęty przez Rade Ministrów w dniu 22 października 2002 r., Rada Ministrów, Warszawa 2002.

\section{Raporty z badań}

25 lat państwa obywatelskiego. Spoteczne oceny samorządności terytorialnej, CBOS, BS/69/2015, Warszawa 2015.

Aktywność społeczna $w$ organizacjach obywatelskich, CBOS, BS/18/2012, Warszawa 2012.

Bandarzewski K., Ekspertyza dotyczaca aktualnych podstaw prawnych i zmian niezbędnych dla rozwoju budżetów partycypacyjnych na poziomie lokalnym w Polsce, Warszawa 2013, www.maszglos.pl (dostęp 15.11.2016).

Co łaczy Polaków?, CBOS, BS/168/2013, Warszawa 2013.

Czapiński J., Diagnoza społeczna 2015, red. J. Czapiński, T. Panek, Warszawa 2015. Czapiński J., Kapitat społeczny, [w:] Diagnoza społeczna 2013, red. J. Czapiński, T. Panek, Warszawa 2013. 
Czy trzeba chodzić na wybory? Przyczyny absencji wyborczej, CBOS, BS/118/2011, Warszawa 2011.

Ewaluacja Poznańskiego Budżetu Obywatelskiego 2015, http://www.poznan.pl/ mim/ main/ewaluacja-poznanskiego-budzetuobywatelskiego2015,p,15574,27284, 28881.html (dostęp 28.04.2016).

Ewaluacja Poznańskiego Budżetu Obywatelskiego 2016, http://www.poznan. $\mathrm{pl} / \mathrm{mim} / \mathrm{main} /$ poznanski-budzet-obywatelski-2016,p,15574,29813.html (dostęp 28.04.2016).

Jak wybierać wójtów, burmistrzów, prezydentów miast?, CBOS, BS/17/2002, Warszawa 2012.

Małe ojczyzny - poczucie przynależności Polaków, CBOS, BS/151/2009, Warszawa 2015.

Motywy niegłosowania, CBOS, nr 161/2015, Warszawa 2015.

Nastroje społeczne we wrześniu, CBOS, BS/131/2016, Warszawa 2016.

O wyborach samorzadowych, CBOS, BS/71/2002, Warszawa 2002.

$O$ wyborach samorzadowych w ostatnich dniach kampanii, CBOS, BS/179/2002,

Warszawa 2002.

Oceny instytucji publicznych, CBOS, BS/43/2016, Warszawa 2016.

Polacy o nepotyzmie w życiu publicznym, CBOS, BS/124/2012, Warszawa 2012.

Polacy o swoim przywiazaniu do miejsca zamieszkania $i$ kraju, CBOS, BS/165/2015, Warszawa 2015.

Polacy o wrześniowym referendum zarzadzonym przez prezydenta Bronisława Komorowskiego, CBOS, 121/2015, Warszawa 2015.

Polacy o wyborach wtadz gminnych, CBOS, 152/2014, Komunikat z Badań, Warszawa 2015, http://www.cbos.pl/SPISKOM.POL/2014/K_152_14.PDF (dostęp 15.11.2016).

Polacy o zarobkach różnych grup zawodowych, CBOS, BS/127/2013, Warszawa 2013. Postulowany termin wyborów parlamentarnych, CBOS, BS/106/2004, Warszawa 2004. Przed druga tura wyborów prezydenckich, CBOS, BS/404/140/90, Warszawa 1994. Przed wyborami samorzadowymi, CBOS, BS/150/2014, Warszawa 2014.

Przyczyny absencji $w$ wyborach parlamentarnych i prezydenckich, CBOS, BS/189/2005, Warszawa 2005.

Psychologiczne charakterystyki elektoratów partyjnych, CBOS, BS/138/2015, Warszawa 2015.

Raport ,, Najlepsze działania promocyjne polskich miast i regionów. Edycja 2015-

2016", http://marketingmiejsca.com.pl/media/uploaded/raportpaw48nyvsn3/

Raport_Najlepsze_dzialania_promo_polskich_miast_i_regionow_Raport_ 2015 -2016.pdf (dostęp 23.04.2016).

Referendum uwłaszczeniowe $i$ w sprawie rozdysponowania majątku narodowego,

CBOS, BS/23/23/96, Warszawa 1996.

Wartości i normy, CBOS, BS/111/2013, Warszawa 2013.

Więzi społeczne $i$ wzajemna pomoc, CBOS, BS/24/2008, Warszawa 2008. 
Woolcock M., The Place of Social Capital in Understanding Social and Economic Outcomes, OECD 2016.

Wybory do Parlamentu Europejskiego w powyborczych deklaracjach Polaków,

CBOS, BS/96/2014, Warszawa 2014.

Wybory samorzadowe, CBOS, BS/94/2002, Warszawa 2002.

Wybory samorzadowe - znaczenie, zainteresowanie oraz deklaracje udziału

w gtosowaniu, CBOS, BS/132/2010, Warszawa 2010.

Zaufanie spoteczne, CBOS, BS/18/2016, Warszawa 2016.

Zaufanie w stosunkach międzyludzkich, CBOS, 29/2014, Warszawa 2014.

Zmiany w psychologicznych profilach elektoratów partyjnych, CBOS, 19/2011,

Warszawa 2011.

\section{Monografie}

Almond G.A., Verba S., The Civic Culture: Political Attitudes and Democracy in Five Nations, Princeton 1963.

Almond G.A., Verba S., The Civic Culture Revisited, London 1989.

Arato A., Chohen J.L., Civil Society and Political Theory, Cambridge 1995.

Arczewska M., Wspótpraca międzysektorowa przy tworzeniu polityk publicznych dotyczacych spraw społecznych i ochrony środowiska, Warszawa 2011.

Arendt H., Kondycja ludzka, Warszawa 2000.

Arystoteles, Polityka, Warszawa 1964.

Banaszak B., Prawo konstytucyjne, wyd. 6 zm., Warszawa 2012.

Banaszak B., Prawo wyborcze obywateli, Warszawa 1996.

Banfield E.C., Civility and Citizenship, New York 1991.

Barad K., Diffracting Diffraction: Cutting Together-Apart, Paralax 2014.

Barad K., Meeting the Universe Half Way, Quantum Physics and the Entanglement of Matter and Meaning, Durham, New York-London 2007.

Batliwala S., Brown L.D., Transnational Civil Society: An Introduction, Bloomfield CT 2006.

Bauman Z., Dwa szkice o moralności ponowoczesnej, Warszawa 1994.

Baylis J., Smith S., Globalizacja polityki światowej. Wprowadzenie do stosunków międzynarodowych, Kraków 2008.

Beck U., Społeczeństwo ryzyka. W drodze do innej nowoczesności, Warszawa 2002.

Beck U., Władza i przeciwwładza w epoce globalnej. Nowa ekonomia polityki światowej, Warszawa 2005.

Beck U., Gernsheim E., Miłość na odległość. Modele życia w epoce globalnej, Warszawa 2013.

Becker H.S., Outsiderzy. Studia z socjologii dewiacji, Warszawa 2009. 
Bellamy R., Shaw J., Making European Citizens: Civic Inclusion in a Transnational Context, Basingstoke 2006.

Bobryk, A., Odrodzenie narodowe Polaków w Republice Litewskiej 1987-1997, Toruń 2006.

Bokajło W., Dziubka K., Społeczeństwo obywatelskie, Wrocław 2001.

Braidotti R., Po człowieku, tłum. J. Bednarek, A. Kowalczyk, Warszawa 2013.

Braidotti R., Podmioty nomadyczne. Ucieleśnienie i różnica seksualna $w$ feminizmie wspótczesnym, thum. A. Derra, Warszawa 2009.

Brown L.D., Creating Credibility: Legitimacy and Accountability for Transnational Civil Society, Bloomfield, CT 2008.

Brown T., Change by Design: How Design Thinking Transforms Organizations and Inspires Innovation, New York 2011.

Buczkowski J., Podstawowe zasady prawa wyborczego w III Rzeczypospolitej, Lublin 1998.

Cackowski Z., Życie ludzkie. Źródło i miara wartości, Lublin 2001.

Castells M., The Power of Identity, Oxford 2013.

Castells M., The Rise of Network Society, Oxford 2000.

Castells M., Sieci oburzenia i nadziei. Ruchy społeczne w erze interentu, Warszawa 2013.

Castells M., Siła tożsamości, Warszawa 2008.

Castells M., Spoleczeństwo sieci, Warszawa 2007.

Castells M., Władza komunikacji, Warszawa 2013.

Chodubski A., Kacprzak L., Pająk K., Instytucje państwa a spoteczeństwo obywatelskie, Piła 2009.

Chwalba A., Polacy w stużbie Moskali, Warszawa-Kraków 1999.

Cichocki R., Podmiotowość spoleczności lokalnych, Poznań 1996.

Cichocki R., Podmiotowość w spoteczeństwie, Poznań 2003.

Cichocki R., Wskaźniki jakości życia mieszkańców Poznania, Poznań 2005.

Cichocki R., Cichocki P., Jabkowski P., Życie w Lesznie 2005, Poznań 2006.

Cichocki R., Cichocki P., Jabkowski P., Życie w Lesznie 2009. Studia nad jakościa życia, Poznań 2010.

Cichocki R., Kilarska A., Życie w Lesznie 2014. 25 lat przemian, Poznań 2014.

Codogni P., Wybory czerwcowe 1989 roku, Warszawa 2012.

Creighton J.L., The Public Participation Handbook, San Francisco 2005.

Crick B., Citizens: Towards a Citizenship Culture, Oxford 2001.

Czaputowicz J., Teorie stosunków międzynarodowych. Krytyka i systematyzacja, Warszawa 2007.

Cześnik M., Partycypacja wyborcza Polaków, Warszawa 2009.

Cześnik M., Partycypacja wyborcza w Polsce. Perspektywa porównawcza, Warszawa 2007.

Dalton R.J., Citizen Politics: Public Opinion and Political Parties in Advanced Industrial Democracy, New York 2002. 
De Landa M., Philosophy and Simulation: The Emergence of SyntheticReason, London and New York 2011

Di Palma G., To Craft Democracy: An Essay on Democratic Transitions, Los Angeles 1990.

Diamond L., Developing Democracy: Towards Consolidation, Baltimore 1999.

Długosz D., Wygnański J., Obywatele wspótdecydują. Przewodnik po partycypacji spotecznej, Warszawa 2005.

Dolnicki B., Partycypacja społeczna w samorzadzie terytorialnym, Warszawa 2014.

Drucker P.F., The Knowledge Economy, Boston 1998.

Dryzek J., Deliberative Democracy and Beyond, Oxford 2000.

Dryzek J., Souvereign Virtue: The Theory and practice of Equality, Cambridge 2000.

Dudek A., Pierwsze lata III Rzeczypospolitej (1989-2001), Kraków 2002.

Durkheim É., O podziale pracy społecznej, Warszawa 1999.

Dybel P., Wróbel S., Granice polityczności. Od polityki emancypacji do polityki życia, Warszawa 2008.

Dziubka K., Obywatelskość jako ,, virtu” podmiotu demokracji, Wrocław 2001.

Easton D., A Systems Analysis of Political Life, New York 1965.

Encyklopedia samorzadu terytorialnego, red. K. Miaskowska-Daszkiewicz, B. Szmulika, Warszawa 2010.

Etzioni A., The Active Society, New York 1998.

Etzioni A., From Empire to Community: A New Approach to International Relations, New York 2004.

Evatt C., Feld B., Dawcy i biorcy, Gdańsk 2001.

Filar P., Kubicki P., Miasto w działaniu, Warszawa 2012.

Florini A., The Third Force: The Rise of Transnational Civil Society, Tokyo-Washington 1999.

Foucault M., Trzeba bronić spoleczeństwa. Wyktady w Collège de France, Warszawa 1998.

Frączak P., Rogaczewska M., Wygnański K., Stan społeczeństwa obywatelskiego. Próba diagnozy, Warszawa 2005.

Fromm E., Rewolucja nadziei. Ku uczłowieczonej technologii, Poznań 1996.

Fukuyama F., Zaufanie: kapitat społeczny a droga do dobrobytu, Warszawa-Wrocław 1997.

Gadamer H.-G., Prawda i metoda. Zarys hermeneutyki filozoficznej, Kraków 1993. Gastil J., Levine P., The Deliberation Democracy Handbook, San Francisco 2005. Gąciarz B., Instytucjonalizacja samorządności. Aktorzy i efekty, Warszawa 2004. Giza A., Przybylska A., Partycypacja obywatelska: od teorii do praktyki spolecznej, Warszawa 2014.

Goffman E., Analiza ramowa. Esej z organizacji i doświadczenia, Kraków 2010. Goldhagen D.J., Gorliwi kaci Hitlera. Zwyczajni Niemcy i Holocaust, Warszawa 1999. Górski R., Bez państwa. Demokracja uczestniczaca w działaniu, Kraków 2007. 
Grabowska M., Spoteczeństwo obywatelskie w Polsce A.D. 2012, Warszawa 2012. Grant A., Dawaj i bierz, Warszawa 2014.

Green G.P., Haines A., Asset Building \& Community Development, London 2002. Grzela J., Teoria i praktyka wspótpracy regionalnej na przykładzie Regionu Morza Battyckiego, Kielce 2010.

Habermas J., Strukturalne przeobrażenia sfery publicznej, Warszawa 2008.

Haerpfer Ch., Bernhagen P., Inglehart R.F., Welzel Ch., Democratization, Oxford 2009. Hannerz U., Powiazania transnarodowe. Kultura, ludzie, miejsca, Kraków 2006.

Held D., Global Covenant. The Social Democratic Alternative to the Washington Consensus, Cambridge 2004.

Held D., Global Transformations. Politics, Economics and Culture, Cambridge 1999. Hirschman A., Lojalność, krytyka, rozstanie. Reakcje na kryzys państwa, organizacji i przedsiębiorstwa, Kraków 1995.

Holmes St., Sunstein C.R., Koszt praw. Dlaczego wolność zależy od podatków, Warszawa 2003.

Hroch, M., Mate narody Europy, Wrocław 2003.

Iriye A., Global Community: The Role of International Organizations in the Making of the Contemporary World, Berkeley 2002.

Jałowiecki B., Łukowski W., Społeczności lokalne, teraźniejszość i przyszłość, Warszawa 2006.

Jarczyk M., Aktywna spoteczność lokalna, Lublin 2002.

Juchacz P.W., O potrzebie wykorzystania nowych modeli partycypacji publicznej w aktywizacji obywateli wspólnot samorzadowych, Poznań 2007.

Kaldor M., The Global Civil Society. An Answer to War, Cambridge 2003.

Kaldovar M., Vojevoda I., Democratization in Central and Eastern Europe, London-New York 1999.

Kalisiak-Mędelska M., Partycypacja społeczna na poziomie lokalnym jako wymiar decentralizacji administracji publicznej w Polsce, Łódź 2015.

Karwat M., Figuranctwo jako paradoks uczestnictwa. Eseje przewrotne, Warszawa 2004.

Kasińska-Metryka A., Prezydenci Rzeczypospolitej Polskiej 1989-1999, Kielce 2000.

Kean J., Global Civil Society?, Cambrigde 2003.

Kębłowski W., Budżet partycypacyjny. Ewaluacja, Warszawa 2014.

Kębłowski W., Budżet partycypacyjny, krótka instrukcja obsługi, Warszawa 2013. Kłusak M., Od literatury do polityki, Elbląg 2016.

Kłusak M., Państwo w polityce. Kryzys europejskiego modelu przywództwa, Elbląg 2016.

Kolczyński M., Strategie komunikowania politycznego, Katowice 2008.

Koncepcja Good governance - refleksje do dyskusji, Warszawa 2008.

Korzeniowski K., Poczucie podmiotowości - alienacji politycznej. Uwarunkowania psychospołeczne, Poznań 1991. 
Kozłowski S., Upodmiotowienie społeczności lokalnych w okresie transformacji systemowej $w$ Polsce, Warszawa 2015.

Kraszewski D., Mojkowski K., Budżet obywatelski w Polsce, Warszawa 2014.

Kryszeń G., Standardy prawne wolnych wyborów parlamentarnych, Białystok 2007. Krytyka polityczna, Partycypacja. Przewodnik krytyki politycznej, Warszawa 2012. Krzysztofek K., Szczepański M.S., Zrozumieć rozwój - od społeczeństw tradycyjnych do informacyjnych, Katowice 2002.

Kurczewski J., Lokalne społeczności obywatelskie, Warszawa 2003.

Leszczyńska K., Rzady Rzeczypospolitej Polskiej (1989-2005), Torun 2007.

Leszczyńska K., Senat Rzeczypospolitej Polskiej w latach 1989-2011, Lublin 2015. Linz J.J., Stepan A., Problems of Democratic Transition and Consolidation:

Southern Europe, South America, and Post-Communist Europe, Baltimore 1997.

Lipset S.M., Homo politicus. Spoleczne podstawy polityki, przeł. G. Dziurdziuk-Kraśniewska, Warszawa 1998.

Łukaszewski W., Szanse rozwoju osobowości, Warszawa 1984.

Maszkowska A., Sztop-Rutkowska K., Partycypacja obywatelska - decyzje bliższe ludziom, Białystok 2013.

Meillassoux Q., After Finitude. An Essay on the Necessity of Contingency, New York 2008.

Meillassoux Q., The Number and the Siren, New York 2012.

Meyer G., Ryszka F., Political Participation and Democracy in Poland and West Germany, Warszawa 1991.

Michalak B., Sokala A., Uziębło P., Leksykon prawa wyborczego i referendalnego oraz systemów politycznych, Warszawa 2013.

Mider D., Partycypacja polityczna w internecie. Studium politologiczne, Warszawa 2008.

Miller L., Tak to byto, Warszawa 2009.

Mills C.W., Białe kotnierzyki. Amerykańskie klasy średnie, Warszawa 1965.

Misztal B., Zagadnienia społecznego uczestnictwa i współdziałania. Analiza w świetle teorii i badań socjologicznych, Wrocław 1977.

Miształ W., Kościański A., Rozdroża praktyki i idei społeczeństwa obywatelskiego, Warszawa 2011.

Modrzejewski J., Socjalizacja i uczestnictwo spoleczne. Studium socjopedagogiczne, Poznań 2007.

Mouffe Ch., Dimensions of Radical Democracy. Pluralism, Citizenship, Community, London-New York 1992.

Newcomb Th.M., Turner R.H., Converse Ph.E., Psychologia społeczna. Studium interakcji ludzkich, Warszawa 1970.

Niemi R.G., Junn J., Civic Education: What Makes Students Learn, Yale 2005.

Niewiadomska-Cudak M., Wybory samorzadowe w Łodzi w latach 1990-2006, Toruń 2011. 
Nowak J.S., Społeczeństwo informacyjne. Doświadczenie i przyszłość, Katowice 2006.

Nowak M., Teoria nieracjonalnego działania, Socjologiczne studium na temat wolontariatu i społecznego aktywizmu, Poznań 2015.

Obuchowski K., Adaptacja twórcza, Warszawa 1985.

Osękowski Cz., Referendum 30 czerwca 1945 roku w Polsce, Warszawa 2000.

Osiatyński W., Twoja konstytucja, Warszawa 1997.

Ossowski St., Dzieła, t. 3, Warszawa 1967.

Ostasz L., Etyka elementarno-uniwersalistyczna w zarysie, Kraków 1991.

Paleczny T., Bunt „nadnormalnych”, Kraków 1998.

Paleczny T., Kontestacja. Formy buntu we współczesnym społeczeństwie, Kraków 1997.

Pawłowski T., Pojęcia i metody współczesnej humanistyki, Wrocław 1977.

Pettit P., On the People's Terms: A Republican Theory and Model of Democracy, New York 2014.

Piasecki A.K., Referenda w III RP, Warszawa 2005.

Pietrzyk-Reeves D., Civil Society, Democracy and Democratization, Frankfurt am Main 2015.

Pietrzyk-Reeves D., Idea społeczeństwa obywatelskiego, Toruń 2012.

Pietrzyk-Reeves D., Idea społeczeństwa obywatelskiego, współczesna debata i jej źródła, Wrocław 2004.

Piwowarski W., Słownik katolickiej nauki społecznej, Warszawa 1993.

Podrez E., Moralne uzasadnienie tolerancji. Studium z etyki personalistycznej, Warszawa 1999.

Popper K., Logika odkrycia naukowego, tłum. U. Niklas, Warszawa 1977.

Putnam R., Demokracja $w$ działaniu. Tradycje obywatelskie we współczesnych Włoszech, Warszawa 1993.

Raciborski J., Obywatelstwo w perspektywie socjologicznej, Warszawa 2011.

Rawls J., Teoria sprawiedliwości, Warszawa 2009.

Rospigliosi A., Greener S., Proceeding of the European Conference on Social Media, Brighton 2014.

Rutkowiak J., Uczenie się od outsidera. Perspektywa europejskiej wspótpracy edukacyjnej, Kraków 1997.

Rybicki P., Struktura społecznego świata. Studia z teorii społecznej, Warszawa 1979.

Sartori G., Teoria demokracji, Warszawa 1994.

Schimanek T., Partycypacja obywatelska w społeczności lokalnej, Warszawa 2015.

Sennett R., Razem. Rytuały, zalety i zasady wspótpracy, Warszawa 2013.

Siatkowski A., Kompetencje obywatelskie a aktywność w sferze publicznej, Poznań 2014.

Singer P., One World: The Ethics of Globalization, New Haven 2002.

Sroka J., Deliberacja i rzadzenie wielopasmowe. Teoria i praktyka, Wrocław 2008.

Sunstein C., Sprzeciw w życiu społeczeństw, Warszawa 2006. 
Szafraniec K., Dojrzewajacy obywatele dojrzewajacej demokracji: o stylu politycznej obecności młodych, Warszawa 2012.

Szalkiewicz W.K., Praktyki manipulacyjne $w$ polskich kampaniach wyborczych, Kraków-Legionowo 2014.

Szczegóła L., Bierność obywateli. Apatia polityczna w teorii demokratycznej partycypacji, Warszawa 2013.

Szczepański M.S., Cnoty i instytucje obywatelskie w spoleczności lokalnej, Tychy 2001. Szczepański M.S., Śliz A., Obywatel w lokalnej społeczności. Studia i szkice socjologiczne, Tychy-Opole 2001.

Sześciło D., Cześnik M., Markowski R., Obywatele i wybory, Warszawa 2013.

Szewczyk A., Społeczeństwo informacyjne - problemy rozwoju, Warszawa 2007.

Sztompka P., Kapitat społeczny. Teoria przestrzeni międzyludzkiej, Kraków 2016.

Sztompka P., Socjologia. Analiza społeczeństwa, Kraków 2002.

Sztompka P., Zaufanie: fundament społeczeństwa, Kraków 2007.

Tocqueville A. de, O demokracji w Ameryce, Warszawa 2005.

Tomala M., Czarny R.M., Wymiar pótnocny Unii Europejskiej. Studium rozwoju, Kielce 2009.

Walzer M., Toward a Global Civil Society, New York 1995.

Weber M., Polityka jako zawód i powołanie, Kraków 1998.

Węglarz B., Ewolucja lokalnej demokracji przedstawicielskiej w Polsce po 1989 roku, Kraków 2013.

Wilkin J., Efektywność a sprawiedliwość, Warszawa 1997.

Wilson E.O., Socjobiologia, Poznań 2000.

Wnuk-Lipiński E., Socjologia życia publicznego, Warszawa 2008.

Wnuk-Lipiński E., Świat międzyepoki. Globalizacja, demokracja, państwo narodowe, Kraków 2004.

Wojnicki J., Trudna droga do demokracji. Europa Środkowo-Wschodnia po 1989 roku, Warszawa 2002.

Wojtyła K., Osoba i czyn oraz inne studia antropologiczne, Lublin 2000.

Young H.P., Sprawiedliwy podziat, Warszawa 2003.

Zieleniewski J., Organizacja zespołów ludzkich, Warszawa 1976.

Ziembiński Z., Etyczne problemy prawoznawstwa, Wrocław 1972.

Ziembiński Z., O pojmowaniu sprawiedliwości, Lublin 1992.

Znamierowski Cz., Wina i odpowiedzialność, Warszawa 1957.

Żerkowska-Balas M., Kozaczuk A., Obywatele i wybory, Warszawa 2013. 


\section{Artykuły w pozycjach zwartych i czasopismach}

Abramowicz B., Koncepcja demokracji deliberatywnej jako odpowiedź na postulaty usprawnienia demokracji przedstawicielskiej, „Ruch Prawniczy, Ekonomiczny i Socjologiczny" 2011, nr 4.

Adam T., Fasadowość instytucji referendum ogólnokrajowego - wybrane zagadnienia, [w:] Aktualne problemy referendum, red. B. Tokaj, A. Feja-Paszkiewicz, B. Banaszak, Warszawa 2016.

Antoszewski A., Demokratyzacja w Polsce w świetle współczesnej tranzytologii, [w:] Dylematy polskiej demokracji, red. Ł. Danel, J. Kornaś, Kraków 2012.

Antoszewski A., Istota władzy samorządowej, [w:] Polityka lokalna. Właściwości determinanty, podmioty, red. E. Ganowicz, L. Rubisz, Toruń 2008.

Antoszewski A., Samorzad jako pole rywalizacji politycznej, [w:] 20 lat samorzadu terytorialnego w Polsce. Sukcesy, porażki, perspektywy, red. K. Mieczkowska-Czerniak, K. Radzik-Maruszak, Lublin 2012.

Arnstein S.R., Drabina partycypacji, [w:] Partycypacja. Przewodnik krytyki politycznej, Warszawa 2012.

Barad K., Erasers and erasures: Pinch's unfortunate 'uncertainty principle', „Social Studies of Science” 2011, vol. 41(3).

Barad K., On touching - the inhuman that therefore I am, differences, „A Journal of Feminist Studies" 2012, vol. 23(3).

Barad K., Posthumanist performativity: Toward an understanding of how matter comes to matter, „Signs: Journal of Women in Culture and Society” 2003, vol. 28.

Bartczak S., Lokalna egzekutywa u progu czwartek kadencji wyborów bezpośrednich. Wnioski z analizy ilościowej, „Samorząd Terytorialny e-Politikon Kwartalnik Naukowy Ośrodka Analiz Politologicznych Uniwersytetu Warszawskiego" 2014, nr XI.

Bartz B., Realia $i$ wyzwania w europejskim procesie rozwoju społeczeństwa cywilnego, [w:] Polski samorzad terytorialny w procesie integracji z Unia Europejska, red. B. Nawrot, J. Pokładecki, Poznań 2003.

Beetham D., Liberal democracy and the limits of democratization, „Political Studies" 1992, vol. 40, no. 1.

Białek Ł., Przeglad bezpośrednich inwestycji zagranicznych w Europie Środkowej i Wschodniej, „Biuletyn Europy Środkowej i Wschodniej” 2012, nr 3.

Bieńkowska E., Termin nie jest dobry!, „Nowa Res Publica” 1997, nr 3(102).

Boldrin M., Canova F., Inequality and convergence in Europe's regions: reconsidering European regional policies, „Economic Policy” 2002, vol. 16/32.

Bonsón E., Royo S., Ratkai M., Citizens'engagement on local governments' Facebook sites. An empirical analysis: The impact of different media and content types in Western Europe, Analyse of social media, „Government Information Quarterly" 2015, vol. 32. 
Booth J.A., Richard P.B., Civil society, social capital and democratization in Central America, „The Journal of Politics” 1998, vol. 60, no. 3.

Boryczka E., Tożsamość Łodzi, czyli o prawdzie tego miasta, [w:] Nowoczesne miasto. Badania, instrumenty, analizy, red. Z. Przygodzki, M.E. Sokołowicz, Łódź 2008.

Budzyńska E., Podzielane czy dzielące? Wartości społeczeństwa polskiego, [w:] Wartości, postawy i więzi moralne $w$ zmieniającym się spoleczeństwie, red. J. Mariański, L. Smyczek, Kraków 2008.

Bukowski A., Władza, terytorium, tożsamość. Społeczne konstruowanie regionu, [w:] Zarządzenie przestrzenią. Globalizacja, etniczność, władza, red. A. Bukowski, M. Lubaś, J. Nowak, Kraków 2006.

Burchard-Dziubińska M., Budżet obywatelski jako partycypacyjna forma wspótrzadzenia, „Studia i Prace Wydziału Nauk Ekonomicznych i Zarządzania” 2014, t. 2, nr 37.

Carothers T., The end of transition paradigm, „Journal of Democracy” 2002, vol. 13, no. 1.

Cichosz M., Pozycjonowanie oferty politycznej na przykładzie wyborów do Parlamentu Europejskiego w Polsce w 2004 roku, [w:] Kampania wyborcza: marketingowe aspekty komunikowania politycznego, red. B. Dobek-Ostrowska, Wrocław 2005.

Coleman J., Social capital in the creation of human capital, „The American Journal of Sociology" 1988, vol. 94.

Cześnik M., Uczestnictwo wyborcze a podaż w polskim systemie politycznym - komentarz do badań, [w:] Obywatele i wybory, red. D. Sześciło, M. Cześnik, R. Markowski, Warszawa 2013.

Dahl R.A., The problem of civic competence, „Journal of Democracy” 1992, vol. 3 , no. 4 .

Darendorf R., Zagrożone spoleczeństwo obywatelskie, [w:] Europa i spoleczeństwo obywatelskie. Rozmowy w Castel Gandolfo, red. K. Michalski, Kraków 1994.

Diamond L., Rethinking civil society: Toward democratic consolidation, „Journal of Democracy" 1994, vol. 5, no. 3.

Dumała A., Uczestnicy transnarodowi - podmioty niezależne czy kontrolowane przez państwa?, [w:] Państwo we wspótczesnych stosunkach międzynarodowych, red. E. Haliżak, I. Popiuk-Rysińska, Warszawa 1995.

Dziekanowska M., Tożsamość społeczna a globalizacja, „Zeszyty Naukowe Uniwersytetu Szczecińskiego, nr 517, Studia Sociologica” 2008, nr 18.

Gajewski S., Jakubowski A., Prawne problemy udziału mieszkańców w sesjach rady gminy i posiedzeniach jej komisji, [w:] Partycypacja społeczna w samorzadzie terytorialnym, red. B. Dolnicki, Warszawa 2014.

Gay G., Pang V.O., Stanley W.B., Expanding Conceptions of Community and Civic Competence for a Multicultural Society, „Theory and Research in Social Education" 1992, vol. 23. 
Gdulewicz E., Partie polityczne i system wyborczy w Rzeczypospolitej Polskiej, [w:] Ustrój polityczny i gospodarczy współczesnej Polski, red. W. Skrzydło, Lublin 1996.

Geodecki T., Procesy konwergencji i polaryzacji $w$ regionach Unii Europejskiej, „Zeszyty Naukowe Akademii Ekonomicznej w Krakowie” 2006, nr 714.

Glińska E., Sposoby badania wizerunku miejsca, „Samorząd Terytorialny” 2011, nr 11.

Gliński P., Sektor obywatelski w słabej demokracji, [w:] Polska po przejściach. Barometr społeczno-ekonomiczny, red. M. Deniszczuk, J. Supińska, Warszawa 2003.

Gulczyński M., Alternatywne orientacje w politologii, „Almamer, Wyższa Szkoła Ekonomiczna, Zeszyty Naukowe" 2009, nr 1(54).

Hryniewicz J.T., Analiza funkcjonowania samorządu lokalnego w oparciu o kluczowe kategorie nauk o zarzadzaniu: misje, cele, własność, kontekst organizacyjny i efektywność, [w:] 20 lat samorządu terytorialnego w Polsce. Sukcesy, porażki, perspektywy, red. K. Mieczkowska-Czerniak, K. Radzik-Maruszak, Lublin 2012.

Hübner D., Wpływ członkostwa w Unii Europejskiej na wzrost gospodarczy w Polsce, [w:] Strategia szybkiego wzrostu gospodarczego w Polsce, red. G. Kołodko, Warszawa 2004.

Itrich-Drabarek J., Problemy sfery publicznej, „Studia Politologiczne” 2009, vol. 14. Jakubowska-Branicka I., Mentalność demokratyczna a dogmatyzm. Przemiany postaw społeczeństwa polskiego $w$ procesie demokratyzacji, [w:] Wartości, postawy $i$ więzi moralne $w$ zmieniajacym się społeczeństwie, red. J. Mariański, L. Smyczek, Kraków 2008.

Janus A., Polityczna partycypacja lokalna wyborcza i referendalna, [w:] Samorzad lokalny w Polsce, red. S. Michałowski, A. Pawłowska, Lublin 2004.

Karwat M., Outsiderskie odmiany apolityczności, „Almamer. Wyższa Szkoła Ekonomiczna. Zeszyty Naukowe" 2009, nr 1(54).

Karwat M., Polityka i apolityczność, [w:] Interpretacje polityki, red. M. Szyszkowska, Warszawa 1991.

Karwat M., Rodzaje teorii w polityce, [w:] Czym jest teoria w politologii, red. Z. Blok, Warszawa 2011.

Karwat M., Uwikłanie jako korelat i koszt uczestnictwa, [w:] Metafory polityki, red. B. Kaczmarek, Warszawa 2013.

Kaźmierczak S., Podmiot samorzadu terytorialnego, [w:] Ustrój i funkcje samorzadu terytorialnego. Studia i szkice, red. H. Rota, Wrocław 1993.

Kaźmierczak T., Partycypacja publiczna: pojęcie, ramy teoretyczne, [w:] Partycypacja publiczna. O uczestnictwie obywateli w życiu wspólnoty lokalnej, red. A. Olech, Warszawa 2011. 
Kentnowska K., Prawo do informacji w spoteczeństwie informacyjnym z uwzględnieniem środków elektronicznych, [w:] Partycypacja społeczna w samorzadzie terytorialnym, red. B. Dolnicki, Warszawa 2014.

Kijowski D.R., Partycypacja obywatelska w samorzadowych procesach decyzyjnych-zagadnienia ogólne, ,Samorząd Terytorialny” 2010, nr 1-2.

Kim B.J., Political efficacy, community collective efficacy, trust and extroversion in the information society: Differences between online and offline civic/political activities, „Government Information Quarterly” 2015, vol. 32.

Kolczyński M., Kampania zmarnowanych szans - polskie doświadczenia z wyborów do Parlamentu Europejskiego w 2004 roku, [w:] Kampania wyborcza: marketingowe aspekty komunikowania politycznego, red. B. Dobek-Ostrowska, Wrocław 2005.

Koncepcja ustrojowa i instytucjonalna II filara Unii Europejskiej, [w:] Unia Europejska, t. II, Gospodarka - Polityka - Wspólpraca, red. W.M. Góralski, Warszawa 2007.

Kopińska V., Key civic competences: Beetwen modern and postmodern perspectives, „Edukacja Dorosłych” 2014, nr 1.

Koselleck R., Trzy światy obywatelskie? Wprowadzenie do porównawczej semantyki społeczeństwa obywatelskiego w Niemczech, Anglii i Francji-zarys dziejów teorii, [w:] Europa i społeczeństwo obywatelskie. Rozmowy w Castel Gandolfo, red. K. Michalski, Kraków 1994.

Kowalik J., Referendum odwoławcze w gminie - instytucja wyborców czy wybieranych?, „Preferencje Polityczne: Postawy. Identyfikacje. Zachowania” 2014, nr 8.

Kowalska I., Partycypacja społeczna w kształtowaniu budżetu jednostki samorzadu terytorialnego - budżet partycypacyjny, ,Economisc and Management” 2014, $\mathrm{nr} 4$.

Kręcisz W., System wyborczy, [w:] Polskie prawo konstytucyjne, red. W. Skrzydło, Lublin 1998.

Kuklinski J.H., Quirk P.J., Conceptual fundations of citizen competence, „Political Behaviour" 2001, no. 2(23).

Kwiatkowska M., Sady obywatelskie jako przykład demokracji partycypacyjnej, „Samorząd Terytorialny” 2013, nr 6.

Langton R., What is citizen participation, [w:] Citizen Participation in America: Esseys on the State of the Art, ed. R. Langton, Lexington 1977.

Leszczyńska K., Instytucja referendum ogólnokrajowego zarządzanego przez Prezydenta za zgoda Senatu, [w:] Instytucja prezydenta w Trzeciej Rzeczypospolitej. Model konstytucyjny i praktyka polityczna, red. T. Słomka, „Studia Politologiczne" 2016, t. 42.

Leszczyńska K., Organy samorzadu terytorialnego, [w:] Organy władzy publicznej w świetle Konstytucji Rzeczypospolitej Polskiej z 2 kwietnia 1997 roku, red. Z. Szeliga, Lublin 2006. 
Leszczyńska K., Referendum i obywatelska inicjatywa ustawodawcza w Trzeciej Rzeczypospolitej Polskiej, [w:] Stan i perspektywy demokracji bezpośredniej w Polsce, red. M. Marczewska-Rytko, Lublin 2010.

Lupia A., Deliberation disconnected: What it takes to improve civic competence, „Law and Contemporary Problems” 2002, vol. 63, no. 3.

Łabędź K., Partycypacja obywatelska na poziomie lokalnym - formy i ograniczenia, „Przegląd Politologiczny” 2015, nr 4.

Łuczak A., Wizerunek miasta, „Samorząd Terytorialny” 2001, nr 1-2.

Łukowski W., Partycypacja, czyli o trudnościach w dzieleniu się władza, „Zoon Politikon" 2012, nr 3.

Magryś R., Kim są katolicy selektywni?, „Nowa Res Publica” 1997, nr 3(102).

Makowski G., Przeglad prawno-instytucjonalnych ram konsultacji społecznych na poziomie samorzadu terytorialnego, [w:] Prawo a partycypacja publiczna. Bilans monitoringu 2012, red. P. Sobiesiak-Penszko, Warszawa 2013.

Małecka-Łyszczek M., Partycypacja w ramach public governance, [w:] Partycypacja spoleczna w samorzadzie terytorialnym, red. B. Dolnicki, Warszawa 2014.

Martela B., Aktywność obywatelska w ramach inicjatyw nieformalnych. Przyczynek do refleksji, „Acta Universitasis Lodziensis. Folia Sociologica” 2011, nr 38.

Megler L., Z liderami czy bez liderów? Partycypacja na przykładzie nowych ruchów miejskich, „Animacja Życia Publicznego” 2013, nr 3.

Melchior M., Tożsamość jednostki - ciagtość i zmiana (rozważania w oparciu o analizę doświadczenia biograficznego Ocalonych z Zagłady), [w:] Od kontestacji do konsumpcji, red. M. Kempny, K. Kiciński, E. Zakrzewska-Manterys, Warszawa 2004.

Michałowski S., Samorzad terytorialny a spoleczeństwo obywatelskie, [w:] Samorząd terytorialny III Rzeczypospolitej. Dziesięć lat doświadczeń, red. S. Michałowski, Lublin 2002.

Miruć A., Obywatelska inicjatywa uchwałodawcza, „Samorząd Terytorialny” 2010, $\mathrm{nr} 1-2$.

Misuraca G., Codagnone C., Rossel P., From practice to theory and back to practice: Reflexivity in measurement and evaluation for evidence-based policy making in the information society, „Government Information Quarterly” 2013, vol. 30.

Misztal B., Tożsamość jako pojęcie i zjawisko spoteczne $w$ zderzeniu z procesami globalizacji, [w:] Tożsamość bez granic, red. E. Budakowska, Warszawa 2005.

Mollo T., Konsultacje komunalne jako klasyczna forma partycypacji spotecznej, [w:] Partycypacja spoleczna w samorzadzie terytorialnym, red. B. Dolnicki, Warszawa 2014.

Mularska-Kucharek M., Podmiotowość i partycypacja społeczna $w$ warunkach lokalnych, „Wieś i Rolnictwo” 2011, nr 2(151). 
Musiał-Karg M., Metody zwiększania frekwencji wyborczej. Polska a doświadczenia innych państw, „Środkowoeuropejskie Studia Polityczne” 2011, nr 2.

Nawrot B., Miejsce ,inicjatyw niezależnych” na lokalnej scenie politycznej w Polsce, „Przegląd Politologiczny” 2009, nr 1.

Nawrot B., Postawy i zachowania mieszkańców wobec samorządu terytorialnego na poziomie matych miast $i$ wsi, [w:] Wtadza lokalna a reforma samorzadowa w Polsce, red. P. Dobrowolski, S. Wróbel, Katowice 1995.

Nikitorowicz J., Edukacja regionalna jako podstawa kreowania społeczeństwa obywatelskiego, [w:] Kierunki rozwoju edukacji w zmieniajacej się przestrzeni spolecznej. Księga jubileuszowa dedykowana profesorowi doktorowi habilitowanemu Michałowi Balickiemu, red. A. Cudowska, Białystok 2011.

Niewiadomska-Cudak M. Cudak A., Skuteczność referendów lokalnych w sprawie odwołania organów gminy w kontekście propozycji legislacyjnych dotyczacych frekwencji, „Zeszyty Naukowe Wyższej Szkoły lnformatyki, Zarządzania i Administracji w Warszawie" 2014, nr 1(26).

O’Donnel G., Illusions about consolidation, „Journal of Democracy” 1996, vol. 7, no. 2.

Olech A., Kiedy mieszkańcy uczestnicza w podejmowaniu decyzji, [w:] Przepis na uczestnictwo. Diagnoza partycypacji publicznej w Polsce, red. A. Olech, t. II, Warszawa 2013.

Olech A., Kaźmierczak T., Modele partycypacji publicznej, [w:] Partycypacja publiczna. O uczestnictwie obywateli w życiu wspólnoty lokalnej, red. A. Olech, Warszawa 2011.

Olech A., Sobiesiak-Penszko P., Partycypacja publiczna w Polsce. Diagnoza i rekomendacje, numer specjalny, „Biuro Analiz i Opinii” 2013, nr 3.

Olejniczak-Szałowska E., Członkostwo wspólnoty samorządowej, „Samorząd Terytorialny" 1996, nr 5.

Olszewski E., Polacy do Parlamentu Europejskiego w 2009 roku, [w:] Rzeczpospolita Polska 1989-2009. Problemy wybrane, red. K. Leszczyńska, Torun 2010.

Orłowska-Bednarz M., Sołectwo jako przykład demokracji bezpośredniej, [w:] Stan i perspektywy demokracji bezpośredniej w Polsce, red. M. Marczewska-Rytko, Lublin 2000.

Parekh B., The cultural plurality of liberal democracy, ,Political Studies” 1992, vol. 40.

Peisert A., Demokracja deliberatywna: utopia czy ratunek dla demokratycznych wartości, „Kultura Liberalna” 2010, nr 2(52).

Piasecki A.K., Demokracja bezpośrednia w Polsce po 1989 r., „Przegląd Sejmowy" 2006, nr 1.

Piasecki A.K., Inicjatywa obywatelska w praktyce politycznej III RP, „Państwo i Społeczeństwo" 2010, $\mathrm{nr} 2$.

Pietrzyk-Reeves D., O wzajemnej złożonej relacji pomiędzy porządkiem obywatelskim a demokratycznym, [w:] Samotność idei? Społeczeństwo obywatelskie we współczesnym świecie, red. B. Krauz-Mozer, P. Borowiec, Kraków 2007. 
Pietrzyk-Reeves D., Weak civic enagagement? Post-communist participation and democratic consolidation, „Polish Sociological Review” 2008, no. 1(161).

Podemski K., Uczestnictwo w życiu politycznym, [w:] Jednostka wobec władzy, red. M. Ziółkowski, B. Pawłowski, R. Drozdowski, Poznań 1994.

Przeworski A., Co decyduje o trwałości demokracji?, „Civitas” 1998, nr 2.

Putnam R., Tuning in, tuning out: The strange disappearance of social capital in America, „Political Science and Politics” 1994, no. 28(4).

Rabczewska M., Społeczne aspekty bezpośrednich wyborów, wójta, burmistrza i prezydenta miasta, [w:] Przywództwo lokalne a kształtowanie demokracji partycypacyjnej, red. S. Michałowski, K. Kuć-Czajkowska, Lublin 2008.

Rachwał M., Przymus wyborczy a legitymizacja władzy politycznej, „Środkowoeuropejskie Studia Polityczne" 2012, nr 4.

Rachwał M., Referenda $w$ sprawie odwołania organu gminy przed uplywem kadencji-doświadczenia lat 2006-2010, [w:] Wieloaspektowość samorzadności gminnej w Polsce, red. B. Nawrot, J. Pokładecki, Poznań 2011.

Rachwał M., Referenda w sprawie odwołania organu samorzadu terytorialnego - doświadczenia lat 2010-2014, „Kwartalnik Naukowy OAP UW e-Politikon" 2014, nr 11.

Raciborski J., Absencja wyborcza: obraz i uwarunkowania zjawiska, [w:] Naród - władza-spoteczeństwo, red. A. Jasińska-Kania, J. Raciborski, Warszawa 1996.

Raciborski J., Zachowania wyborcze Polaków w warunkach zmiany systemu politycznego, [w:] Wybory i narodziny demokracji w krajach Europy Środkowej i Wschodniej, red. J. Raciborski, Warszawa 1991.

Radiukiewicz A., O obywatelskości we współczesnym świecie. Kierunki zmian i przestrzenie rozwoju, „Zoon Politikon” 2012, nr 3.

Regulski J., Samorzadność i spoteczeństwo obywatelskie - kilka pytań $i$ wiele watpliwości, ,Samorząd Terytorialny” 2013, nr 3.

Reykowski J., Ukryte założenia normatywne jako osiowy skladnik mentalności, [w:] Orientacje społeczne jako element mentalności, red. J. Reykowski, K. Skarżyńska, M. Ziółkowski, Poznań 1990.

Rulka M., Próg frekwencyjny w gminnych referendach odwoławczych, „Infos” 2016, nr 1.

Rustow D., Transition to democracy: Toward a comparative model, „Comparative Politics" 1970, vol. 2.

Santos B. de Sousa, Participatory budgeting in Porto Alegre: Toward a redistributive democracy, „Politics \& Society” 1998, no. 4.

Schedler A., What is democratic consolidation?, „Journal of Democracy” 1998, vol. 9, no. 2.

Schmitter P., Karl T., The conceptual travels of transitologists and consolidologists: How far to the east should they attempt to go?, „Slavic Review” 1994, vol. 53 , no. 1 . 
Seters P., Aproaching global civil society, [w:] Critical Mass, The Emergence of Global Civil Society, eds J.W. Walker, A. Thompson, Waterloo 2008.

Sidor M., Konsultacje spoleczne $w$ największych polskich miastach: prawne aspekty - praktyczne zastosowanie, [w:] Partycypacja społeczna w samorzadzie terytorialnym, red. B. Dolnicki, Warszawa 2014.

Skarżyńska K., Aktywność i bierność polityczna, [w:] Podstawy psychologii politycznej, red. K. Skarżyńska, Poznań 2002.

Skarżyńska K., Aktywność i bierność polityczna, [w:] Psychologia polityczna, red. K. Skarżyńska, Poznań 1999.

Skotnicki K., Funkcje wyborów, [w:] Prawo wyborcze Rzeczypospolitej Polskiej i problemy akcesji Polski do Unii Europejskiej. Materiały XLIV Ogólnopolskiej Konferencji Katedr i Zakładów Prawa Konstytucyjnego - Olsztyn 25-27 kwietnia 2002 r., red. A. Sylwestrzak, J. Juchniewicz, M. Augustyniak,T. Podlejski, S. Bułajewski, D. Ossowska, M. Dąbrowski, Olsztyn 2003. Sokołowicz M., Boryczka E., Marka Łodzi jako czynnik budujący tożsamość Łódzkiego Obszaru Metropolitalnego, [w:] Lódzka metropolia. Problemy integracji społecznej i przestrzennej, red. A. Suliborski, Z. Przygocki, Łódź 2010.

Somers M., Citizenship and the place of the public sphere: Law, community, and the political culture in the transition of democracy, „American Sociological Review" 1997, no. 58(5).

Sommerfeldt R.J., The civility of social capital: Public relations in the public sphere, civil society and democracy, „Public Relations Review” 2013, vol. 39.

Souza C., Participatory budgeting in Brazilian cities: limits and possibilities in building democratic institutions, „Environment \& Urbanization” 2001, vol. 13, no. 1(04).

Szaranowicz-Kusz M., Budżet partycypacyjny w Polsce, „Infos” 2016, nr 1.

Szczepański M.S., Tożsamość regionalna - w kręgu pojęć podstawowych, [w:] Badania nad tożsamościa regionalna, red. A. Matczak, Łódź-Ciechanów 1999.

Sześciło D., Konsultacje społeczne w gminie w świetle orzecznictwa sąów administracyjnych, „Samorząd Terytorialny” 2014, nr 1-2.

Synak B., Małe ojczyzny w globalnej wiosce, [w:] Globalizacja i my. Tożsamość lokalna wobec trendów globalnych, red. R. Piekarski, M. Graban, Kraków 2003.

Taylor Ch., Kiedy mówimy społeczeństwo obywatelskie, [w:] Europa i społeczeństwo obywatelskie. Rozmowy w Castel Gandolfo, red. K. Michalski, Kraków 1994.

Tyshchenko Y., Modele komunikacji politycznej: partie polityczne i spoleczeństwo obywatelskie, [w:] Ukraińskie Niepodległe Centrum Badań Politycznych, Kijów 2010.

Walzer M., Spór o społeczeństwo obywatelskie, [w:] Ani ksiązę, ani kupiec. Obywatel. Idea społeczeństwa obywatelskiego w myśli współczesnej, red. J. Szacki, Kraków 1997.

Waszczyńska K., Wokót problematyki tożsamości, „Rocznik Towarzystwa Naukowego Płockiego" 2014, nr 6. 
Waśkiewicz A., Dobro wspólne i spoteczeństwo obywatelskie w teorii demokracji deliberatywnej i reprezentacji grupowej, [w:] Partycypacja obywatelska. Od teorii do praktyki społecznej, red. A. Przybylski, A. Giza, Warszawa 2014.

Węglarz B., Referenda lokalne w sprawie odwołania organów jednostek samorzadu terytorialnego w czwartej kadencji (lata 2002-2006), „Samorząd Terytorialny" 2007, $\mathrm{nr} 7-8$.

Wiadra H., Southern Europe, Eastern Europe, and comparative politics: „Transitology” and the need for new theory, „East European Politics and Societies" 2002, vol. 15, no. 3.

Więckowska M., Polityczny przymus wyborczy w Polsce Ludowej. Przesłanki wprowadzenia prawnego przymusu wyborczego w czerwcu 1989, [w:] Czas próby. Polski przetom polityczny roku 1989, red. A. Materska-Sosnowska, T. Słomka, „Studia Politologiczne” 2009, t. 15.

Wijnhoven F., Ehrenhard M., Kuhn J., Open government objectives and participation motivations, „Government Information Quarterly” 2015, vol. 32.

Wiśniewski M., Odrębność rozwojowa regionu łódzkiego. Niewykorzystane dziedzictwo królestwa polskiego, „Acta Universitatis Lodziensis. Folia Oeconomica" 2010, nr 245.

Wróbel S., Miejskie ruchy polityczne. Wybrane zagadnienia, [w:] Od teorii do praktyki politycznej, red. M. Kołodziejczak, R. Rosicki, Poznań 2012.

Wróbel S., Powstanie i ewolucja miejskich ruchów politycznych. Przypadek miast górnoślaskich, „Przegląd Politologiczny” 2005, nr 1.

Yakymenko Y., Metodologia analizy dynamiki systemów partyjnych: główne podejścia i osobliwości ich zastosowania w Ukrainie, „Biuletyn Politologiczny" 2011, \#52.

Zakaria F., The rise of illiberal democracy, „Foreign Affairs” 1997, vol. 76, no. 6. Zdybicka Z.J., Analiza pojęcia partycypacji występujacego w filozofii klasycznej, „Roczniki Filozoficzne. Filozofia Teoretyczna” 1970, t. XVIII, z. 1.

Zgiep M., Poza reprezentacją i partycypacją. Demokracja wspótczesna w świetle teorii demokracji deliberatywnej, [w:] Procesy i procedury demokratyczne w Polsce, red. A. Stelmach, Torun 2014.

Żukowski A., Przymus wyborczy - istota, przesłanki i implikacje, „Prawo i Polityka" 2009, z. 1.

\section{Artykuły w prasie codziennej}

Bereszczyński M., Sesje Rady Miejskiej w Łodzi. Prezydent Zdanowskiej znów nie będzie, „Dziennik Łódzki”, 9.04.2014, http://www.dzienniklodzki.pl/ artykul/3395963,sesja-radymiejskiej-w-lodzi-prezydent-zdanowskiej-znownie-bedzie,id,t.html (dostęp 15.11.2016). 
Darda M., Hanna Zdanowska: Mnie polityka nie interesuje, ale dla Łodzi zawsze będę grać ostro, „Dziennik Łódzki”, 17.01.2016, http://www.dzienniklodzki. pl/artykul/9294152, hannazdanowska-mnie-polityka-nie-interesujeale-dla-lodzi-zawsze-bede-grac-ostrowywiad,id,t.html (dostęp 30.01.2016).

Dębicki M., Nauczmy się zadawać pytania, „Rzeczpospolita” 2012, nr 13.

Osiecki G., Potocki M., Referendum przeszło do historii, „Dziennik Gazeta Prawna" 2015, nr 174.

Stelmach S., Dlugowieczni w samorzadach, „Rzeczpospolita”, 6.04.2010.

Winczorek P., Obowiazek głosowania a konstytucja, „Rzeczpospolita” 2003, nr 28.

\section{Źródla internetowe}

Agreement on the European Economic Area, http://www.efta.int/sites/default/files/d ocuments/legal-texts/eea/the-eea-agreement/Main $\% 20 \mathrm{Text} \% 20 \mathrm{of} \% 20$ the\%20Agre ement/ EE Aagreement.pdf (dostęp 14.10.2014).

Aktorzy i dylematy partycypacji-jak dbać o jakość procesów i lepsze uczestnictwo?, „Animacja Życia Publicznego” 2013, nr 3, www.civitas.edu.pl (dostęp 20.12.2016).

Bliżej kadencyjności. Szef sejmowej komisji samorzadu chce zmienić prawo, PAP, http:// samorzad.pap.pl/depesze/wiadomosci_centralne/170047/Blizej-kadencyjnosci-Szefsejmowej-komisji-samorzadu-chce-zmienic-prawo (dostęp 15.11.2016).

Bukowski S.I., The Maastricht Convergence Criteria and Economic Growth in the EMU, http://www.ec.unipg.it/DEFS/uploads/quad24.pdf (dostęp 30.12.2015).

Ganuza E., Baiocchi G., The Power of Ambiguity: How Participatory Budgeting Travels the Globe, ,Journal of Public Deliberation” 2012, vol. 8, no. 2, http:// www.publicdeliberation.net/jpd/vol8/iss2/art8 (dostęp 20.02.2017).

Grzybowski M., Region Morza Battyckiego jako obszar integracji makroregionalnej $w$ Unii Europejskiej, http://webcache.googleusercontent.com/ search? q=cache: I Ozp6NohDMJ:https://www.msz.gov.pl/resource/efff7d4c -826e-4208-a4cd-941 f882da938 :JCR+\&cd=1\&hl=pl\&ct=clnk\&gl=pl (dostęp 30.12.2015).

http://watcher.com.ua/2013/11/29/yevromaydan-ukrayinska-tsyfrova-revolyutsiya-taostanniy-shans-analohovym-politykam-staty-tsyfrovymy/ (dostęp 16.09.2016).

Hyży E., Dzielenie się światem. Nowy feministyczny realizm w ujęciu Karen Ba$\mathrm{rad}$, https://www.academia.edu/28271247/Dzielenie_si\%C4\%99_\%C5\%9Bwiatem.Nowy_feminis tyczny_realizm_w_uj\%C4\%99ciu_Karen_Barad.pdf (dostęp 10.03.2017).

Internet Users in the World, http://www.internetlivestats.com/internet-users/ (dostęp 15.09.2016). 
Izdebski H., Podstawy prawne wprowadzenia instytucji inicjatywy uchwatodawczej mieszkańców do statutów jednostek samorządu terytorialnego, Warszawa 2013, www.maszgłos.pl (dostęp 15.11.2016).

Izdebski K., Ustawa o petycjach. Fundament czy fasada?, Warszawa 2015, www. batory.org.pl (dostęp 15.11.2016).

Kiepsko z inicjatywa ustawodawcza $w$ gminach, www.portalsamorządowy.pl (dostęp 15.11.2016).

Kokoszkiewicz M., Ruchów miejskich życie wewnętrzne, „Animacja Życia Publicznego" 2013, nr 3, www.civitas.edu.pl (dostęp 15.11.2016).

Kubicki P., Ruchy miejskie w Polsce. Próba analizy, www.slideshare.net (dostęp 15.11.2016).

Labovitz C., Ahuja A., The impact of Internet Policy and Topology on Delayed Routing Convergence, http://ieeexplore.ieee.org/xpl/login.jsp?tp=\&arnumber=91 6775\&url=http\%3A\%2F\%2Fieeexp lore.ieee.org\%2Fxpls\%2Fabs_all.jsp\%3Farnumber\%3D916775 (dostęp 15.09.2016).

Lemak W., Partie polityczne jako instytut spoteczeństwa obywatelskiego: problem prawnej regulacji w Ukrainie, http://www.nbuv.gov.ua/old_jrn/soc_gum/ pruk/2010_7/3.pdf (dostęp 30.12.2015).

Liubczenko P., Patrie polityczne jako element społeczeństwa obywatelskiego $i$ ich wptyw na samorząd miejscowy, 2009, http://dspace.nlu.edu.ua/handle/123456789/2318 (dostęp 22.02.2014).

Mojkowski K., Pięć lat inicjatywy lokalnej. Porównanie przepisów dotyczacych inicjatywy lokalnej z praktyka ich stosowania $w$ latach 2010-2014, www. masz głos.pl (dostęp 20.12.2016).

Program kreacji i promocji marki województwa łódzkiego z planem wdrożenia w latach 2012-2016, http://lodzkie.p1/lodzkiemarka/download/805_0c53c94cd87a04d06ca7036f749e3d71 (dostęp 16.09.2016).

Serageldin M., Assessment of Participatory Budgeting in Brazil, Harvard 2005, https://www.mef.gob.pe/contenidos/pol_econ/documentos/Presupuesto_Participativo_Brasil_Efectos.pdf (dostęp 20.02.2017).

Sintomer Y., Herzberg C., Roecke A., Budżet partycypacyjny w Europie - szanse $i$ wyzwania, thum. M. Chustecka, http://ngo.chorzow.eu/_DOKUMENTY/budzet_partycypacyjny_w_europie.pdf (dostęp 20.02.2017).

Siuta-Tokarska B., Zarys wybranych problemów społeczno-gospodarczych Polski $w$ okresie transformacji systemowej a polityka gospodarcza państwa, Uniwersytet Ekonomiczny w Krakowie, http://www.ur.edu.pl/pliki/Zeszyt19/03. pdf (dostęp 2.01.2016).

Sowa J., Wyschnięte źródto? O ewentualnych pożytkach i aktywności społeczeństwa obywatelskiego, „Animacja Życia Publicznego” 2015, nr 1, www.cal. org.pl. (dostęp 2.01.2016).

Sześciło D., Koncepcje ustawowego uregulowania budżetów obywatelskich (partycypacyjnych), Warszawa 2014, www.masz głos.pl (dostęp 14.11.2016). 
Yakymenko Y., Spoleczeństwo obywatelskie w Ukrainie: główne charakterysty$k i, 2004$, http://www.razumkov.org.ua/ukr/article.php?news_id=320 (dostęp 22.02.2014).

Yale Professor Talks Russian Propaganda in Ukraine, http://emorywheel.com/ yale-professortalks-russian-propaganda-in-ukraine/ (dostęp 16.09.2016).

Zarycki T., Wybrane dylematy budowy tożsamości regionalnej, Wrocław 2008, http://www.iss.uw.edu.pl/zarycki/pdf/tozsamosc.pdf (dostęp 13.01.2017).

Zarycki T., Tucholska A., Region, którego miało nie być. Paradoksy tożsamości województwa świętokrzyskiego w kontekście krajowym i europejskim, Wrocław 2004, http://www.iss.uw.edu.pl/zarycki/pdf/swietokrzyskie.pdf (dostęp 10.01.2017).

Zyzik K., Brońmy swego! Czyli NTO w walce o województwo, „Nowa Trybuna Opolska", 18.06.2012, http://www.nto.pl/artykuly-archiwalne/art/4505739, bro nmy-swego-czyli-nto-wwalce-o-wojewodztwo,id,t.html (dostęp 12.09.2016).

Żerkowska-Balas M., Zaremba M., Partycypacja nowych wyborców, Warszawa 2015, www.batory.org.pl (dostęp 15.11.2016).

Żółciak T., Koniec wiecznych burmistrzów. PiS szykuje zmiany w kadencyjności lokalnych władz, www,http://forsal.pl/artykuly/909713,kadencje-samorzad -wojt-burmistrz-prezydentpis-kadencyjnosc.html (dostęp 8.12.2015).

Opracowanie: Mateusz Radziszewski 